\title{
Problems of Operational Safety of Dump Trucks in Open Pit Mine
}

\author{
Boris Gerike ${ }^{1,2}$, Aleksandr Zacharov ${ }^{1}$, Pavel Gerike ${ }^{2}$, and Yuriy Drozdenko ${ }^{1, *}$ \\ ${ }^{1}$ T.F. Gorbachev Kuzbass State Technical University, 650000, Kemerovo, Russia \\ ${ }^{2}$ Institute of Coal of the Siberian Branch of the RAS, 650065, Kemerovo, Russia
}

\begin{abstract}
One of the risk factors for dump trucks drivers is the over-vibration on various parts and control units. This leads to the formation of high intensity of work. To search for the causes of over-vibration it is proposed to use vibration analysis methods. To search for the causes of overvibration it is proposed to use vibration analysis methods in time when dump truck is not moving. This allows the escaping the influence of external factors such as like profile of the road, slope, etc. The analysis of the vibrational signal spectrum allows determining the type of defect with a high degree of reliability.
\end{abstract}

\section{Introduction}

There is a known problem of occupational morbidity of the drivers of dump trucks [1-3], which is associated with over-vibration in the workplace. This requires a reduction in time of relay of the driver, but this is often impossible due to the organization of labor in the pit mine. Despite the continuous improvement in the design of mining dump trucks and their service systems, there is in the level of occupational morbidity among drivers do not decrease $[4,5]$.

Vibrodiagnostic [6-9] is the most acceptable for manufacturing and assembling mining equipment most suitable for searching and identifying various types of mining equipment (including heavy mining dump trucks) [6-9], which allows $90 \%$ confidence [8, 10-13] to identify and diagnose developing defects at an early stage.

\section{Methods of examination}

Vibrodiagnostics refers to functional methods for assessing the technical condition of equipment $[9,11]$, therefore, in principle, it can be used for working loads of dump trucks when driving them on technological roads, during loading and unloading of a transported rock mass. However, when a diagnostic examination of the trucks is to search for defective equipment is more appropriate Parking test, when you set various operation modes of the engine (idling, the nominal rpm maximum allowable rpm when the Parking test), then the disconnect is attached equipment (pump, drive shaft and fan wheel).

\footnotetext{
${ }^{*}$ Corresponding author duv.gmik@kuzstu.ru
} 
The values of vibration velocity $\mathrm{V}$, vibration acceleration a and vibration displacement $\mathrm{S}$ measured in the frequency range $(3-4000 \mathrm{~Hz})$ were chosen as diagnostic features.

Table 1 presents comparative estimates of classes of working conditions with the maximum and permissible levels of vibration acceleration.

Table 1. Comparison of European and Russian classes of working conditions

\begin{tabular}{|c|c|c|c|c|}
\hline \multicolumn{2}{|c|}{$\begin{array}{l}\text { Directive 2002/44/EC } \\
\text { - vibration }[14]\end{array}$} & \multicolumn{3}{|c|}{$\begin{array}{l}\text { Russian classification of working conditions } \\
\text { (general and local vibration) }[15-17]\end{array}$} \\
\hline \multirow{3}{*}{$\begin{array}{l}\text { Invalid level } a> \\
1,15 \mathrm{~m} / \mathrm{s}^{2}\end{array}$} & \multirow{3}{*}{ Red } & 4 & $a_{z}>8,9 \mathrm{~m} / \mathrm{s}^{2} ; a_{y, x}>6,3 \mathrm{~m} / \mathrm{s}^{2}$ & Extreme \\
\hline & & 3.4 & $a_{z}=4,46-8,9 \mathrm{~m} / \mathrm{s}^{2} ; a_{y, x}=3,2-6,3 \mathrm{~m} / \mathrm{s}^{2}$ & \multirow{4}{*}{ Harmful } \\
\hline & & 3.3 & $a_{z}=2,23-4,46 \mathrm{~m} / \mathrm{s}^{2} ; a_{y, x}=1,6-3,2 \mathrm{~m} / \mathrm{s}^{2}$ & \\
\hline \multirow{2}{*}{$\begin{array}{l}\text { Limit level } a= \\
1,15 \mathrm{~m} / \mathrm{s}^{2}\end{array}$} & \multirow{2}{*}{ Yellow } & 3.2 & $a_{z}=1,12-2,23 \mathrm{~m} / \mathrm{s}^{2} ; a_{y, x}=0,79-1,6 \mathrm{~m} / \mathrm{s}^{2}$ & \\
\hline & & 3.1 & $a_{z}=0,56-1,12 \mathrm{~m} / \mathrm{s}^{2} ; a_{y, x}=0,4-0,79 \mathrm{~m} / \mathrm{s}^{2}$ & \\
\hline \multirow{2}{*}{$\begin{array}{l}\text { Acceptable level } \\
a \leq 1,15 \mathrm{~m} / \mathrm{s}^{2}\end{array}$} & \multirow{2}{*}{ Green } & 2 & $a_{z}<0,56 \mathrm{~m} / \mathrm{s}^{2} ; a_{y, x}<0,4 \mathrm{~m} / \mathrm{s}^{2}$ & Accepted \\
\hline & & 1 & $a_{z}=0 \mathrm{~m} / \mathrm{s}^{2} ; a_{y, x}=0 \mathrm{~m} / \mathrm{s}^{2}$ & Optimum \\
\hline
\end{tabular}

Figure 1 shows a diagram of the control points for measuring local vibration in the driver's cab.

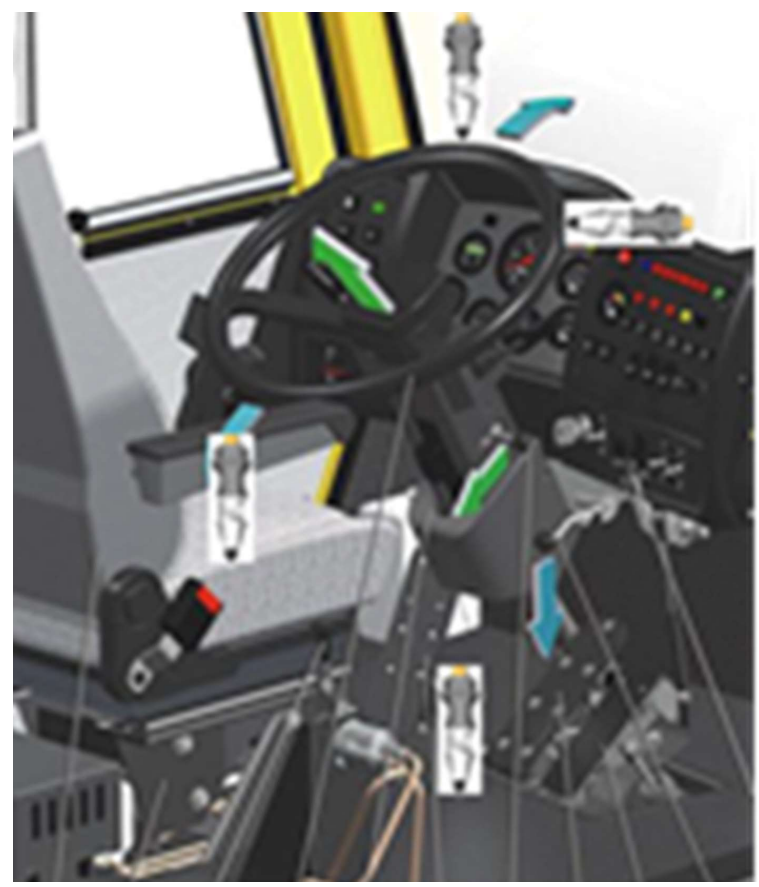

Fig. 1 The scheme of vibration measurement on the driver's seat, driver's cab, and steering wheel

To search for a source of over-vibration was conducted examination units that generate the vibration (diesel engine and generator).

Figure 2 shows a control points scheme of measurement of local vibration on the left side of the diesel engine. A similar vibration measurement scheme was used on the right side of the engine.

Figure 3 shows a control points scheme of measurement of local vibration on the electric generator. 


\section{Measurement result}

The object of the study was chosen dump truck BelAZ-75306, which is operated on the pit mine "Vinogradovsky" PJSC "Kuzbasskaya Toplivnaya Company". During operation, drivers had a subjective feeling of over-vibration. Measurement of vibration level was carried out in accordance with the accepted measurement procedure with the sequential shutdown of the components of the power unit.

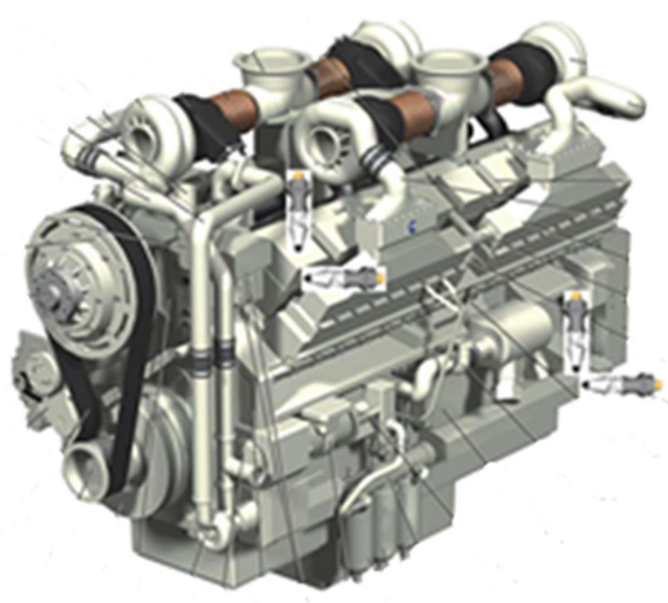

Fig. 2 The scheme of vibration measurement on a diesel engine

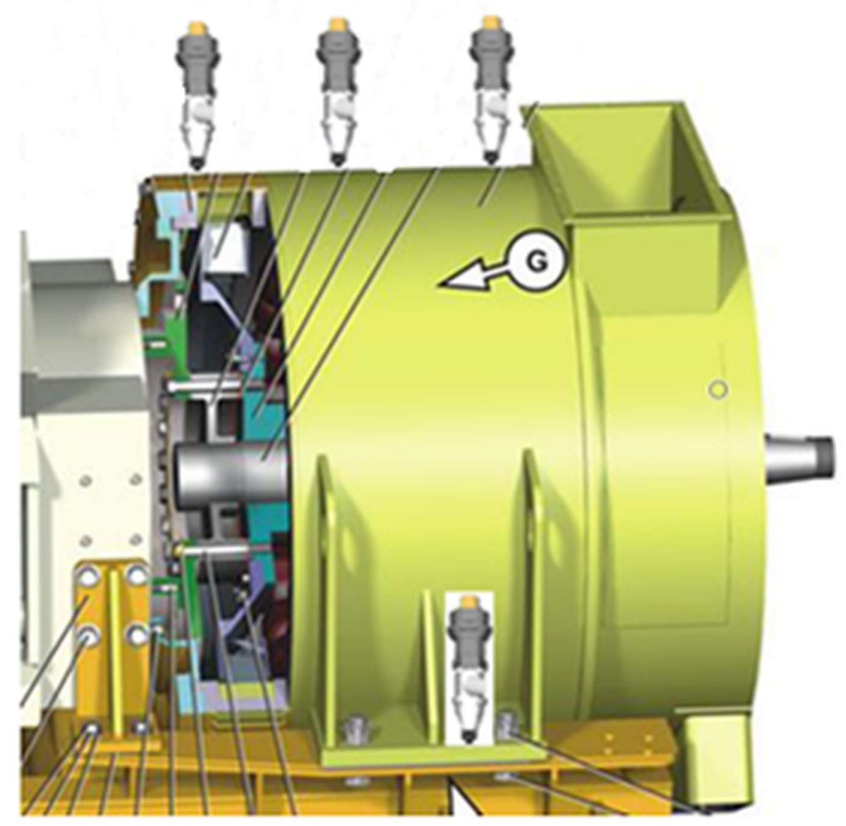

Fig. 3 The scheme of vibration measurement on an electric generator. 
From the analysis of the vibration that affects the driver of the dump truck, it follows that the maximum acceleration is formed on the cab floor in the vertical component amax $=0.77$ $\mathrm{m} / \mathrm{s}^{2}$ at idle, which exceeds the maximum permissible value [a] $=0.5 \mathrm{~m} / \mathrm{s}^{2}[14-17]$. As follows from the spectral analysis of vibration acceleration (figure 4) in some cases, vibration isolation of the cabin passes the mechanical vibrations generated by the engine to the floor of the driver's cab.

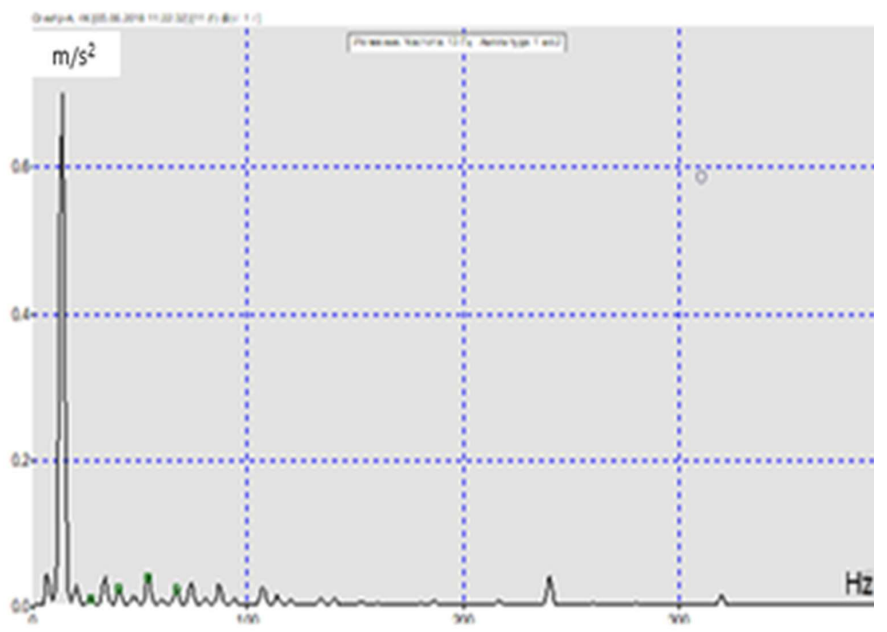

Fig. 4 Spectrum of the vertical component of vibration generated by the engine to the floor of the driver's cab $\mathrm{n}=800 \mathrm{~min}^{-1}, \mathrm{a}=0,77 \mathrm{~m} / \mathrm{s}^{2}$

From the analysis of vibration acting on the driver of the dump truck, it follows that the maximum value of vibration acceleration acting on the hands on the steering wheel (local vibration) reaches the value of $a_{\max }=0.40 \mathrm{~m} / \mathrm{s}^{2}$, which does not exceed the maximum permissible value $[\mathrm{a}]=2.5 \mathrm{~m} / \mathrm{s}^{2}[14-17]$.

Spectral analysis of the results of vibration measurement on the steering wheel indicates poor engine performance (figure 5) - there is the appearance of the second and higher harmonics, there is a harmonic at half the crankshaft speed. All this testifies to the unsatisfactory work of the power supply system of the engine.

Analysis of the test results shows that the main source of mechanical vibrations is a diesel drive dump truck. At the same time, the maximum value of vibration acceleration amax $=27$ $\mathrm{m} / \mathrm{s} 2$, which is less than the maximum permissible value $[\mathrm{a}]=4 \mathrm{~g}$, and the value of vibration velocity, by which the technical condition is estimated, $\mathrm{V}=6,2<[\mathrm{V}]=7,2 \mathrm{~mm} / \mathrm{s}$, which indicates a satisfactory technical condition of the drive system.

Increasing the engine speed from $800 \mathrm{~min}^{-1}$ (idle run) to $1200 \mathrm{~min}^{-1}$ (maximum speed during testing) almost always leads to a decrease in the level of vibration, but the value of vibration acceleration is almost always increasing.

Disconnection of attachments (pump, cardan shaft and fan wheel) has virtually no effect on the overall and local vibration level, although the vibration process pattern is slightly changed. 
a)

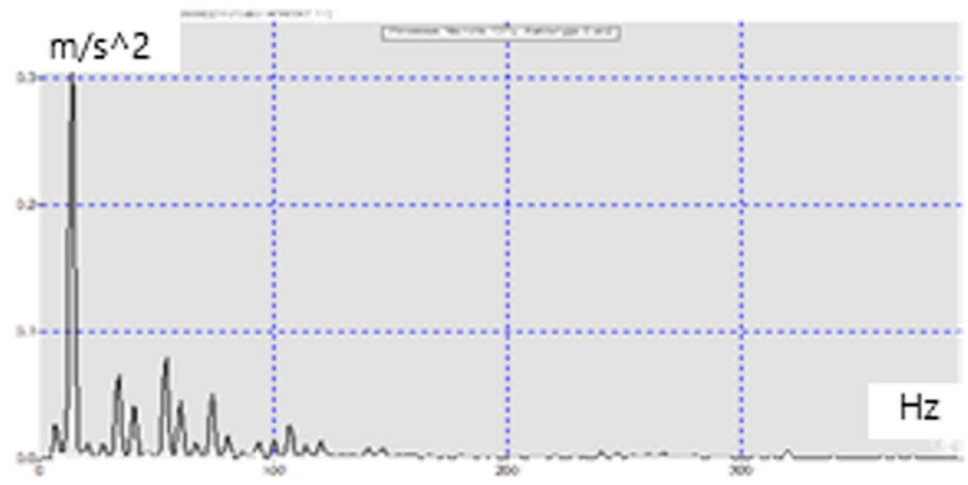

b)

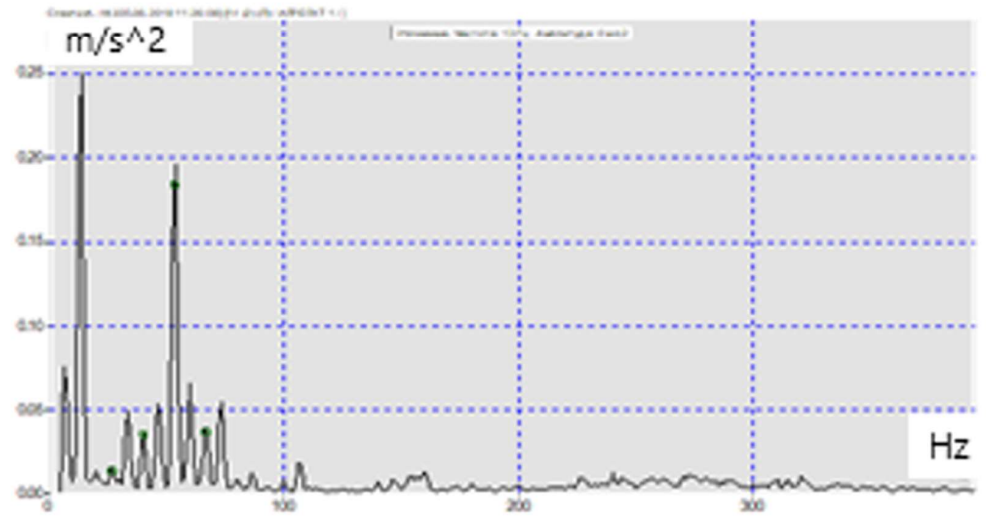

c)

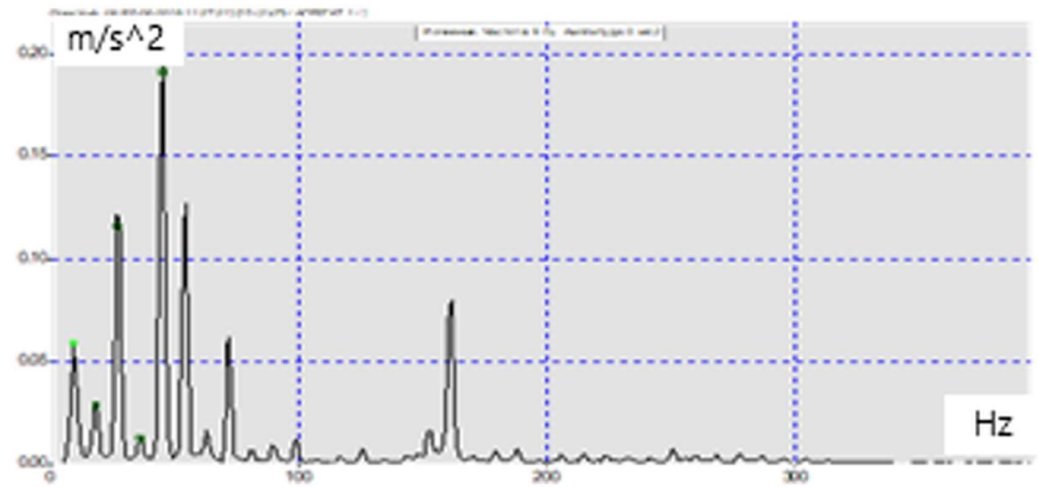

Fig. 5 Spectra of the vibration on the steering wheel: a - vertical component $\left(\mathrm{n}=800 \mathrm{~min}^{-1} ; \mathrm{a}=0,36 \mathrm{~m} / \mathrm{s}^{-}\right.$ $\left.{ }^{2}\right) ; \mathrm{b}$ - quadrature component $\left(\mathrm{n}=800 \mathrm{~min}^{-1} ; \mathrm{a}=0,38 \mathrm{~m} / \mathrm{s}^{-2}\right) ; \mathrm{c}$ - vertical component $\left(\mathrm{n}=1000 \mathrm{~min}^{-1} ; \mathrm{a}=0,31\right.$ $\mathrm{m} / \mathrm{s}^{-2}$ ) 


\section{Conclusion}

Summarizing the above, we can say that:

- the search for sources of increased vibration is possible only using the method of functional diagnostics, namely vibration diagnostics;

- when carrying out diagnostic measurements, it is necessary to exclude the influence of external production factors for the identification of defects in the manufacture, assembly, and operation of dump trucks;

- the spectral composition of vibration processes makes it possible to determine the type of defect with a high degree of reliability (probability $p=0.9$ ) and, when using the Russian classification of working conditions, to determine the degree of danger of the detected defect.

\section{References}

1. L. Saidi, J. Ben Ali, F. Fnaiech, ISA Transactions, 53, 1650-1660 (2014)

2. J. Tuma, 10.1002/9781118797563.ch3 (Dekker mechanical engineering, Berlin, 2014)

3. J. Xiaohang, C. Fangzhou, P. Yayu, Q.Wei \& Qu, Liyan, IEEE Industry Applications Magazine, 10.1109/MIAS.2017.2740470 (2018)

4. L.Jing, M. Zhao, P. Li, X. Xu, Measurement, 111, 1 (2017)

5. E. Kuzin, B. Gerike, Y. Drozdenko et al. IOP Conf. Series: Materials Science and Engineering, 253, 012013 (2017)

6. B. Gerike, I. Panachev, E. Kuzin, E3S Web of Conf., 15, 03008 (2017)

7. G. E. Morales-Espejel, Evolution, 2, 25 (2010)

8. A. Mohamed, S. Sassi, M. Paurobally, Shock and Vibration, 2018, 1913289 (2018)

9. W. Yu, Y. Shao, and C. Mechefske, Engineering Failure Analysis, 54, 103 (2015)

10. K. Heidarbeigi, H. Ahmadi, M. Omid and A. Tabatabaeefar, Journal of Agricultural Technology, 5, 1 (2009)

11. Kelly S. Graham, Advanced vibration analysis (Dekker mechanical engineering, Berlin, 2013)

12. Anil Rana,. Journal of Quality in Maintenance Engineering, 22:2, 180 (2016)

13. B. Gerike, A. Mokrushev, The 9th China-Russia Symposium Coal in the 21st Centuri: Mining, Intelligent Equimpent and Environmental Protection, 213 (2018)

14. Directive 2002/44/EC of the European Parlament and of the Ccouncil of 25 June 2002 (2002)

15. J. Obuchowski et al, Appl. Mech. Mater., 683, 171 (2014)

16. W. Bartelmus, Key Engineering Materials, 588, 184 (2014)

17. Z. Ming, J. Xiaodong, Mechanical Systems and Signal Processing, 94, 129 (2017) 